\title{
Effects of oats on plasma cholesterol and lipoproteins in C57BL/6 mice are substrain specific
}

\author{
Kristina E. Andersson ${ }^{1}$, Tina Immerstrand ${ }^{2}$, Karl Swärd ${ }^{1}$, Björn Bergenståhl ${ }^{2}$, Marie W. Lindholm ${ }^{3}$, \\ Rickard Öste ${ }^{2}$ and Per Hellstrand ${ }^{1}$ \\ ${ }^{1}$ Department of Experimental Medical Science, Lund University, BMC D12, SE-221 84 Lund, Sweden \\ ${ }^{2}$ Department of Food Technology, Engineering and Nutrition, Center for Chemistry and Chemical Engineering, Lund University, \\ Lund, Sweden \\ ${ }^{3}$ Department of Clinical Sciences, Lund University, Lund, Sweden
}

(Received 23 February 2009 - Revised 16 July 2009 - Accepted 28 July 2009 - First published online 20 October 2009)

\begin{abstract}
Cholesterol-lowering effects of oats have been demonstrated in both animals and human subjects. However, the crucial properties of oat-containing diets that determine their health effects need to be further investigated to optimise their use. A mouse model would be a valuable tool, but few such studies have been published to date. We investigated the effects of oat bran on plasma cholesterol and lipoproteins in two substrains of C57BL/6 mice. Western diet was made atherogenic by the addition of $0.8 \%$ cholesterol and $0.1 \%$ cholic acid. After 4 weeks on atherogenic diet, total plasma cholesterol had increased from $1.86-2.53$ to $3.77-4.40 \mathrm{mmol} / 1$. In C57BL/6NCrl mice, inclusion of 27 and $40 \%$ oat bran reduced total plasma cholesterol by 19 and $24 \%$, respectively, reduced the shift from HDL to LDL + VLDL and caused increased faecal cholesterol excretion. There was no effect of oat bran on plasma levels of the inflammatory markers fibrinogen, serum amyloid A or TNF- $\alpha$. Contrary to findings in C57BL/6NCrl mice, there was no sustained effect of oat bran $(27$ or $40 \%)$ on plasma cholesterol in C57BL/6JBomTac mice after 4 weeks of feeding. Thus, C57BL/6NCrl mice fed an atherogenic diet are a good model for studies of physiological effects of oats, whereas a substrain derived from C57BL/6J, raised in a different breeding environment and likely possessing functional genetic differences from C57BL/6N, is considerably less responsive to oats. The present finding that two substrains of mice respond differently to oats is of practical value, but can also help to elucidate mechanisms of the cholesterol-lowering effect of oats.
\end{abstract}

乃-Glucans: Dietary Fibres: Cholesterol: Lipoproteins: Atherosclerosis

Beneficial effects of oats and oat $\beta$-glucans on plasma cholesterol and lipoproteins have been reported in both human subjects $^{(1-5)}$ and animals ${ }^{(6-9)}$. In 1997, Food and Drug Administration approved a health claim stating that 'soluble fibre from food such as oat bran, as part of a diet low in saturated fat and cholesterol, may reduce the risk of heart disease $^{(10)}$, and recent meta-analyses of a large number of human studies on oat fibres support the concept that they lower total and LDL-cholesterol in plasma, with no or little effect on HDL or $\mathrm{TAG}^{(11,12)}$. Some trials investigating the hypocholesterolaemic effect of oats and/or oat $\beta$-glucans do, however, fail to show significant reduction in plasma cholesterol, and when stating the health claim Food and Drug Administration reviewed thirty-three clinical studies, out of which twenty-one showed significant reduction in blood cholesterol by oats, whereas twelve did not ${ }^{(10)}$. The concentration and size of $\beta$-glucans have been suggested to influence their physiological effects, and furthermore, processing, cooking and storage of oat products can change their physico-chemical properties, causing the cholesterollowering effect to be altered or lost ${ }^{(13)}$. Therefore, the effects of $\beta$-glucans may vary depending on the preparation of the food ingredients ${ }^{(1,2)}$. An animal model in which effects of defined preparations of oats and/or $\beta$-glucans can be systematically investigated would be an important tool for clarifying these issues.

The basis for the cholesterol-lowering effect of oats is not definitely known, although components suggested to be responsible are the soluble fibres, $\beta$-glucans, present. These are non-starch polysaccharides composed of $\beta$ - $(1 \rightarrow 4)$ linked glucose units separated by a single $\beta-(1 \rightarrow 3)$-linked glucose unit every two to three units. Several mechanisms of action have been proposed for their effect, including decreased intestinal (re)uptake of dietary cholesterol and bile acids, fermentation in the colon leading to release of carboxylic acids with effects on cholesterol metabolism, as well as effects on glucose uptake and insulin levels ${ }^{(14-20)}$.

The incomplete understanding of the mechanisms by which $\beta$-glucans may lead to reduced cholesterol levels contributes to difficulties in interpreting the divergent outcomes of human studies with regard to oat-containing products. It is not clearly elucidated which role the molecular weight (Mp) of $\beta$-glucans plays and to which extent other components in oats also contribute to the beneficial effects.

Abbreviation: Mp, molecular weight.

* Corresponding author: Kristina E. Andersson, fax +46 46 2113417, email kristina_e.andersson@med.lu.se 
In vitro experiments suggest anti-oxidative and antiinflammatory effects of phenolic acids, sterols, flavonoids and vitamin E ( $\alpha$-tocopherol) present in oats, but little in vivo evidence for this exists ${ }^{(21)}$. Increased understanding of the relevant parameters may allow the development of new oat-containing foods that are attractive to consumers as well as beneficial to health. It would further be desirable to systematically evaluate new products in an animal model before costly human trials are performed.

Studies in hamsters ${ }^{(8)}$, chickens $^{(22)}$ and rats $^{(6,7,9)}$ have previously evaluated the cholesterol-reducing effect of oats or oat $\beta$-glucans. Some of these studies do not compare effects of oat dietary fibre with a control fibre ${ }^{(6,7)}$, which makes it difficult to ascribe the effects to the oat fibres rather than fibres in general. Delaney et al. ${ }^{(8)}$ found similar effects of oat and barley $\beta$-glucans on plasma cholesterol and lipoproteins in hamster, an animal with a lipoprotein profile similar to human subjects. Different animal models may be appropriate for studies of dietary effects of oats depending on the particular goal. A mouse model would be attractive because of the large number of genetic variants available. These can be used to provoke hypercholesterolaemia and atherosclerosis on either high-fat or normal food formulations and can potentially allow mechanisms of action to be efficiently analysed. Furthermore, mice are common laboratory animals that are cost efficient to keep and consume small amounts of food, a consideration of importance when experimental diets are tested. The inbred strain of C57BL/6 mice develops hypercholesterolaemia and eventually atherosclerosis when fed a high-fat diet containing cholesterol and bile acids (atherogenic diet) ${ }^{(23)}$, and has been used extensively in studies of cholesterol-lowering drugs or dietary components such as soya isoflavones ${ }^{(24)}$, psyllium husks ${ }^{(25)}$, persimmon fruits ${ }^{(26)}$ and taurine ${ }^{(27)}$. An early study in wild-type C57BL/6 mice did not reveal any cholesterol-lowering effect of oats ${ }^{(28)}$. Given recent developments in the use of mice in atherosclerosis research, there is, however, ample reason to further consider this species as an experimental model.

The aims of the present study were to evaluate mice as a model for studies of cholesterol-lowering effects of oats. As an initial step, we evaluated the effects of oat bran on plasma cholesterol, lipoproteins and systemic inflammatory markers related to atherosclerosis, and also on faecal cholesterol excretion in $\mathrm{C} 57 \mathrm{BL} / 6$ mice. We found that the substrain C57BL/6NCrl (B6NC) readily responds with sustained lowered plasma cholesterol concentration and reduced levels of LDL + VLDL on an oat bran diet, whereas this was not the case with the substrain C57BL/6JBomTac (B6JB).

\section{Materials and methods}

\section{Animals}

Female C57BL/6NCrl mice were purchased from Charles River laboratories (Sulzfeld, Germany) and C57BL/6JBomTac mice from Taconic (Lille Skensved, Denmark). During an adaptation period of 2 weeks, all mice were fed normal chow (R34 rodent chow, Lactamin, Vadstena, Sweden). At 10-12 weeks of age (body weight 17-21 g), mice were randomly assigned to the experimental groups. The mice had free access to food and water, and were kept in a temperature-controlled environment and $12 \mathrm{~h}$ light cycle environment. All experiments followed national guidelines for the care and use of animals, and were approved by Malmö/Lund regional ethical committee for laboratory animals (M86-05).

\section{Diets}

Experimental diets were designed to resemble a human 'Western' diet, in terms of the contribution of fat, protein and carbohydrate to the total energy intake (41, 16 and $43 \%$, respectively), and were made atherogenic by inclusion of $0.8 \%(\mathrm{w} / \mathrm{w})$ cholesterol and $0.1 \%(\mathrm{w} / \mathrm{w})$ sodium cholate, except where indicated. In initial experiments, a concentration of $0.5 \%$ cholic acid was used, but this was reduced to $0.1 \%$ in the major part of the study to prevent gallstone formation. Control and oat bran diets were adjusted in order to keep the energy ratios constant; for details, see Tables 1 and 2 . DL-Methionine was added to provide a sufficient supply of amino acids and to compensate for differences in methionine contents between oat bran protein and casein ${ }^{(29,30)}$.

The oat bran diets contained 40 or $27 \%$ oat bran (Avena sativa cv. Sang, produced 2007, Lantmännen AB, batch 1008596, Järna, Sweden), pre-milled to particle size less than $0.8 \mathrm{~mm}$. The oat bran had a total fibre content of $16 \%$ (oat bran composition analysed by Eurofins Food, Lidköping, Sweden), whereof $7.2 \%$ was $\beta$-glucans. The $\beta$-glucan

Table 1. Formulation of the atherogenic diets with $0.1 \%$ cholic acid and $0.8 \%$ cholesterol

\begin{tabular}{|c|c|c|}
\hline & $\begin{array}{l}\text { Control diet } \\
\text { (g/kg diet) }\end{array}$ & $\begin{array}{l}27 \% \text { oat bran } \\
\text { diet ( } \mathrm{g} / \mathrm{kg} \text { diet) }\end{array}$ \\
\hline Casein, 80 mesh $^{*}$ & 200 & 146 \\
\hline DL-Met & 3 & 4.5 \\
\hline Maize starch & 272 & 133 \\
\hline Maltodextrin & 100 & 100 \\
\hline Sucrose & 100 & 94 \\
\hline Cellulose & 44 & 0 \\
\hline Butter, anhydrous $†$ & 200 & 176 \\
\hline Maize oil & 10 & 10 \\
\hline Mineral Mix S10026 & 10 & 10 \\
\hline Dicalcium phosphate & 13 & 13 \\
\hline Calcium carbonate & 5.5 & 5.5 \\
\hline Potassium citrate $\cdot 1 \mathrm{H}_{2} \mathrm{O}$ & $16 \cdot 5$ & $16 \cdot 5$ \\
\hline Vitamin Mix V10001 & 10 & 10 \\
\hline Choline bitartrate & 2 & 2 \\
\hline Cholesterol† & $7 \cdot 54$ & 7.59 \\
\hline Sodium cholate & 1 & 1 \\
\hline Oat bran & 0 & 270 \\
\hline \multicolumn{3}{|l|}{ Oat bran contents ( $\mathrm{g} / 270 \mathrm{~g}$ oat bran) $\ddagger$} \\
\hline Protein & & 48 \\
\hline Sucrose & & 6 \\
\hline Starch & & 139 \\
\hline Fat & & 24 \\
\hline Dietary fibres (whereof $\beta$-glucans) $\S$ & & $44(19 \cdot 4)$ \\
\hline Ash & & 9 \\
\hline
\end{tabular}

${ }^{*}$ Casein is $88 \%$ protein

†Anhydrous butter has $230 \mathrm{mg}$ cholesterol $/ 100 \mathrm{~g}$. To compensate for this, extra cholesterol was added to the oat bran diet so that total amount of cholesterol was $8 \mathrm{~g} / \mathrm{kg}$ diet in both diets.

‡ Nutrient contents of oat bran were analysed by Eurofins Food Lidköping, Sweden, 2007.

$\S \beta$-Glucan content was analysed in our laboratory, see Materials and methods for details. 
Table 2. Macronutrient and energy content of the atherogenic diets

\begin{tabular}{lcc}
\hline & Control diet & $27 \%$ oat bran diet \\
\hline Protein (\% energy) & 16 & 16 \\
Carbohydrate (\% energy) & 43 & 43 \\
Fat (\% energy) & 41 & 41 \\
Saturated & 29 & 26 \\
Unsaturated & 10 & 11 \\
Polyunsaturated & 2 & 4 \\
Energy (kJ/g diet) & 19 & 19 \\
\hline
\end{tabular}

* The composition of fat was based on data for maize oil, oat bran and butter from Swedish National Food Administration ${ }^{(39)}$.

content was determined using an enzymatic kit (Megazyme International, Wicklow, Ireland) based on the McCleary ${ }^{(31)}$ method for mixed linkage $\beta$-glucans. The diet with $27 \%$ oat bran thus contains approximately $2 \% \quad \beta$-glucans and $4.4 \%$ total fibre, whereas the diet with $40 \%$ oat bran contains $3.0 \% \beta$-glucans and $6.5 \%$ total fibre. In the control diets, the oat fibres were replaced by 4.4 or $6.5 \%$ microcrystalline

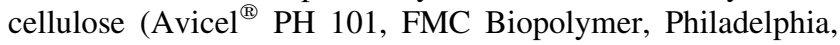
PA, USA), respectively. Table 1 shows the formula for the $27 \%$ oat bran diet with the respective control diet. The diet with $40 \%$ oat bran and its respective control diet were also made according to the formula in Table 1, but the control diet was compensated for the larger proportion of oat protein, sucrose, starch, fat and fibres present in the test diet. In both cases, the control and oat bran diets were matched with respect to dietary fibre, energy and macronutrient contents. The diets were purchased as premixes from Research Diets Inc. (New Brunswick, NJ, USA), to which melted anhydrous butter, maltodextrin, cellulose and oat bran were added in our laboratory by careful mixing. All experimental diets were fed as powder. Feed consumption was determined per cage over 1-week periods and expressed as g consumed per mouse and day.

\section{Molecular weight of $\beta$-glucans in oat bran}

Oat bran samples were extracted with $82 \%$ (v/v) boiling ethanol $(2 \mathrm{~h})$ to inactivate endogenous $\beta$-glucanases. After centrifugation $(9300 \mathrm{~g} ; 15 \mathrm{~min})$, the supernatant was discarded and the residue oven dried $\left(13 \mathrm{~h}\right.$ at $\left.60^{\circ} \mathrm{C}\right)$, pulverised and extracted with $0 \cdot 1 \mathrm{~mol} / \mathrm{l} \mathrm{NaOH}$ for $2 \mathrm{~h}$ at room temperature. After centrifugation $(15000 \mathrm{~g} ; 10 \mathrm{~min})$, the supernatant was neutralised, diluted ten times and filtered through a nylon filter (0.45 $\mu \mathrm{m}$; R04SP04700, GE Water \& Process Technologies). Peak Mp and Mp distribution of $\beta$-glucans were analysed using high-performance size-exclusion chromatography with postcolumn addition of calcofluor, as described by Tosh et al. ${ }^{(32)}$. The Mp of the $\beta$-glucans in the oat bran batches used here was found to be approximately 3.0 MDa.

\section{Experimental protocol}

B6NC and B6JB mice were fed diets either with 27 or $40 \%$ oat bran or with their respective control diets. In each study, mice were initially divided into groups that were housed together in cages of seven or ten animals. Following 2 weeks on regular chow diet, blood samples were drawn to establish baseline values and the different cages were then fed experimental diets. The animals ( $n$ 82) tolerated the studies well, and after 4 or 5 weeks on the experimental diet, mice were sacrificed by cervical dislocation under isoflurane anaesthesia.

\section{Plasma cholesterol and TAG}

At weeks 0 (study start), 1, 2 and 4, blood samples were collected after $4 \mathrm{~h}$ fasting, from vena saphena into EDTAcoated microvette tubes. Samples were taken after $4 \mathrm{~h}$ fasting to achieve stable conditions without starvation. Plasma was prepared by centrifuging whole blood at $5000 \mathrm{~g}$ for $10 \mathrm{~min}$ at $4^{\circ} \mathrm{C}$. Samples were stored at $-80^{\circ} \mathrm{C}$ until assayed. To protect the structure of the lipoproteins during freezing, $10 \%$ sucrose was added to plasma aliquots aimed for lipoprotein analysis. Total plasma cholesterol and TAG levels were determined colorimetrically using Infinity cholesterol/TAG Liquid Stable reagent (ThermoTrace, Noble Park, Vic., Australia).

\section{Plasma lipoproteins}

Plasma lipoproteins were separated by electrophoresis in $0.8 \%$ agarose gels in barbital buffer according to the method of Noble ${ }^{(33)}$, using a Sebia Hydragel 7 Lipoprotein(E), K20 chamber (Sebia, France). With this method, apo B-containing lipoproteins (LDL, LDL and VLDL) can be separated from HDL due to their individual charges. After staining of the gels with Sudan black and densitometric scanning (BioRad GS 800 Calibrated Densitometer and Quantity One quantitation software), the relative amounts of HDL and VLDL + LDL were calculated from the intensity of the bands. Values of VLDL and LDL were summed since the bands are not clearly distinguishable. With this method, it is possible to analyse very small amounts of plasma $(2-3 \mu l)$, but the method only yields relative amounts in each sample, not absolute concentrations of lipoproteins.

\section{Plasma inflammatory markers}

To investigate whether oat bran had an impact on low-grade systemic inflammation related to the development of atherosclerosis, plasma from mice fed $27 \%$ oat bran for 4 weeks was analysed with commercially available ELISA kits for the acute-phase proteins fibrinogen (Immunology Consultants Laboratory, Inc. Newberg, OR, USA) and serum amyloid A (Tridelta Development Ltd, Maynooth, Ireland) and for the proinflammatory cytokine TNF- $\alpha$ (R\&D Systems, Inc., Minneapolis, MN, USA).

\section{Faecal sampling and analyses}

Faeces were collected from each cage during $24 \mathrm{~h}$ at baseline and after 4 weeks of experimental diet administration. The collected faeces (from ten or seven animals) were lyophilised and weighed. Lipids were then extracted from the material by a modified version of the protocol by Hara \& $\operatorname{Radin}^{(34)}$. Triplicates of $80-150 \mathrm{mg}$ lyophilised faecal material from each sample were extracted in hexane-isopropanol $(3: 2 \mathrm{v} / \mathrm{v})$ with $0.005 \%$ 2,6-di-tert-butyl-4-methylphenol. A total of 
$5 \mathrm{ml}(2 \mathrm{ml}+3 \times 1 \mathrm{ml}$ wash $)$ of the extract was dried under $\mathrm{N}_{2}$, and the residue was redissolved in $1 \mathrm{ml}$ isopropanol + Triton $\mathrm{X}-1001 \%{ }^{(35)}$. This solution was used in duplicate $(2 \times 5 \mu \mathrm{l})$ for the cholesterol assay, which was the same as the one used for the plasma total cholesterol analysis. The total amount of cholesterol in the sample was divided by the number of mice per cage to yield the average cholesterol excretion in faeces (mg/mouse and day).

\section{Data presentation and statistical analysis}

Data are presented as mean values with their standard errors. Significance of differences between means was tested by Student's $t$ test for unpaired data in GraphPad Prism software (GraphPad Software Inc., San Diego, CA, USA). Values of $P<0.05$ were considered to indicate statistical significance.

\section{Results}

\section{C57BL/6 substrains and plasma cholesterol}

Inclusion of oat bran in an atherogenic diet prominently attenuated the ensuing hypercholesterolaemia in the B6NC mouse substrain, whereas only a transient effect was seen in B6JB mice (Fig. 1). This difference is of interest with respect to the analysis of genetic effects and mechanisms of action of

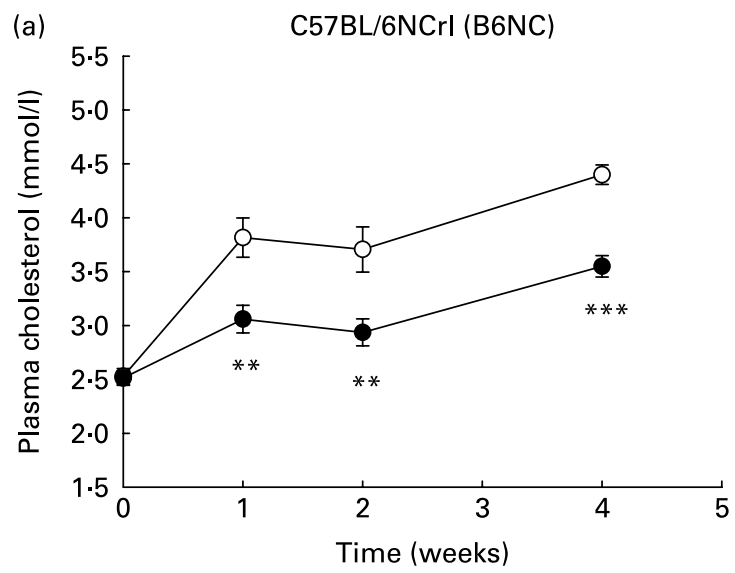

(b)

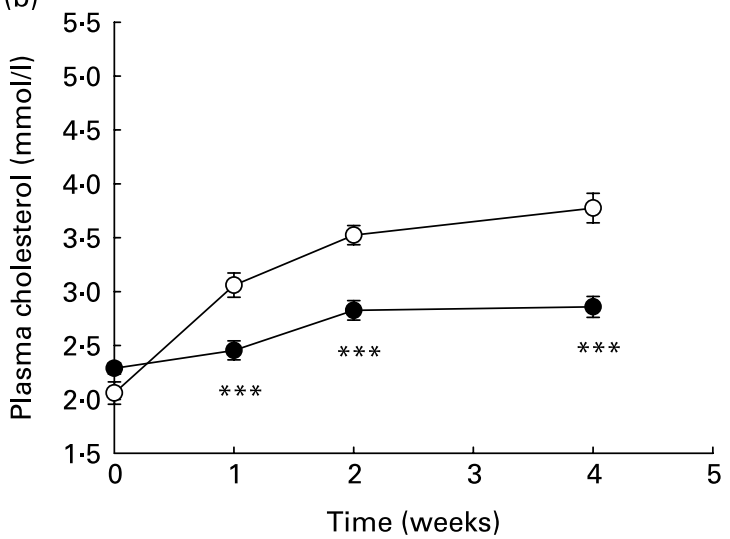

oats and $\beta$-glucans, and is also of obvious practical importance for the testing of dietary components in mice. Since the purpose of the present study was to establish a mouse model for evaluating effects of oats and oat $\beta$-glucans, we concentrate here on the B6NC strain for the majority of the results. Data from B6JB mice are shown for comparison. The effects of 27 and $40 \%$ oat bran cannot be directly compared since the total amounts of fibre differ in the two diets and their respective control diet (4.4 v. 6.5\%). Both concentrations do, however, lower plasma cholesterol significantly, and the effect is slightly more pronounced with $40 \%$ oat bran (Fig. 1(b)). There was no effect of $40 \%$ oat bran on plasma cholesterol in the B6JB substrain (Fig. 1(d)). The data in Fig. 1(d) were obtained using a concentration of cholate of $0.5 \%$ in the atherogenic diet, whereas the data in Fig. 1(a)-(c) were obtained using $0.1 \%$ cholate. The reason for this change is that we noticed more variation in cholesterol levels, lower weight gain and a tendency to gallstone formation using the higher cholate concentration.

\section{Body weight and feed intake}

The mice gained weight throughout the study. When B6NC mice were fed $40 \%$ oat bran, they gained more weight than those fed control fibre (Table 3), which was accompanied by a greater food intake in this group (Table 3). With $27 \%$ oat
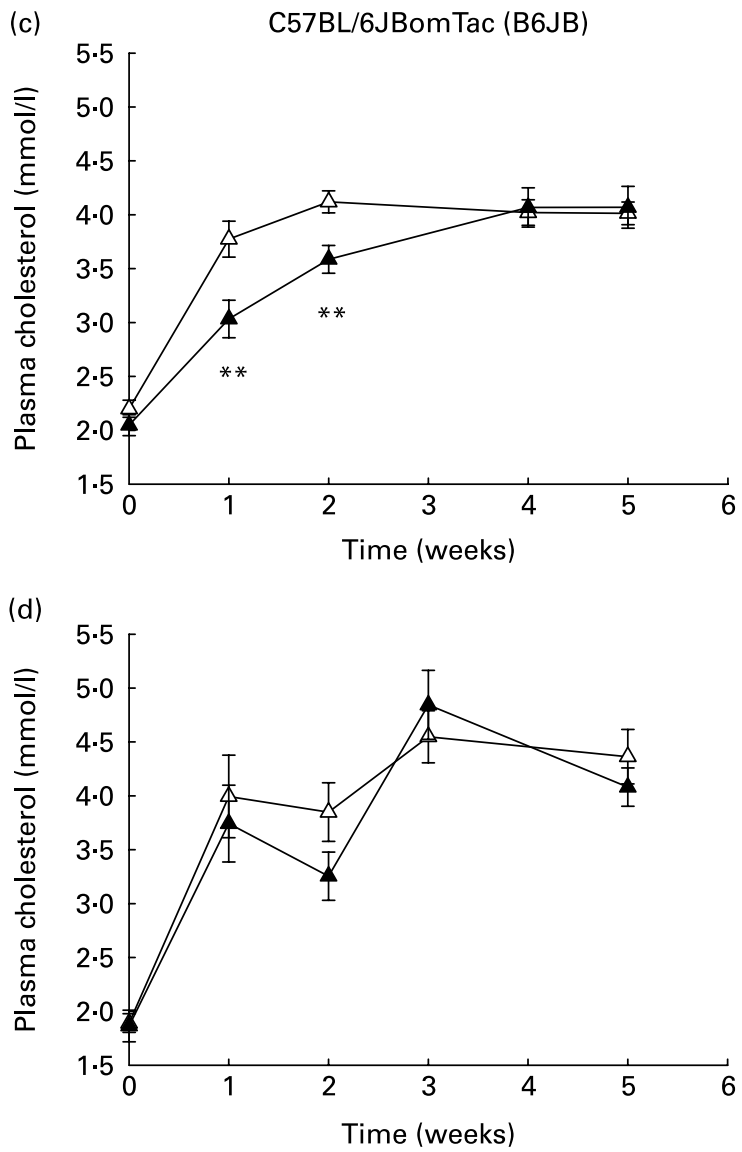

Fig. 1. Effects of oats on plasma cholesterol differ between substrains of C57BL/6 mice. Data show plasma cholesterol at baseline (normal chow, week 0 ) and after 1-5 weeks on atherogenic diet in C57BL/6NCrl mice with $27 \%((\mathrm{a}), n 10)$ or $40 \%$ ((b), $n$ 14) oat bran, and in C57BL/6JBomTac mice with 27\% ((c), $n$ 10) or $40 \%((\mathrm{~d}), n 7)$ oat bran. Data are presented as mean values with their standard errors. $(\bullet)$, Oat bran; $(\bigcirc)$, Control. Statistical analysis was performed with unpaired Student's $t$ test. ${ }^{\star \star} P<0.01$ or ${ }^{\star \star \star} P<0.001$. 
Table 3. Initial weight, body weight gain, feed intake and faecal cholesterol excretion in C57BL/6 mice fed atherogenic diets for 4 weeks (Mean values with their standard errors)

\begin{tabular}{|c|c|c|c|c|c|c|c|c|c|c|c|c|c|}
\hline & \multicolumn{3}{|c|}{ Initial weight (g) } & \multicolumn{3}{|c|}{ Body weight gain (g) } & \multicolumn{3}{|c|}{$\begin{array}{c}\text { Feed intake } \\
\text { (g/mouse and day) }\end{array}$} & \multicolumn{2}{|c|}{$\begin{array}{l}\text { Dry faeces } \\
\text { (g/mouse } \\
\text { and } 24 \mathrm{~h})\end{array}$} & \multicolumn{2}{|c|}{$\begin{array}{c}\text { Faecal } \\
\text { cholesterol } \\
\text { (g/mouse } \\
\text { and } 24 \mathrm{~h} \text { ) }\end{array}$} \\
\hline & Mean & SEM & $n$ & Mean & SEM & $n$ & Mean & SEM & $n$ & & $n$ & & $n$ \\
\hline \multicolumn{14}{|l|}{ C57BL/6NCrl } \\
\hline Control ( $4.4 \%$ total fibre) & $18 \cdot 3$ & 0.3 & 10 & $2 \cdot 6$ & 0.4 & 10 & $2 \cdot 1$ & 0.03 & $3+$ & 0.17 & $1 \dagger$ & $7 \cdot 0$ & $1 \dagger$ \\
\hline $27 \%$ oat bran & $18 \cdot 2$ & 0.2 & 10 & $2 \cdot 7$ & 0.2 & 10 & $2 \cdot 1$ & 0.07 & $3 \dagger$ & 0.21 & $1 \dagger$ & $9 \cdot 1$ & $1 \dagger$ \\
\hline Control ( $6.5 \%$ total fibre) & 21.5 & 0.3 & 14 & 0.7 & 0.3 & 14 & $2 \cdot 1$ & 0.03 & $8 \dagger$ & ND & - & ND & - \\
\hline $40 \%$ oat bran & $21 \cdot 1$ & 0.2 & 14 & $1 \cdot 8^{*}$ & 0.2 & 14 & $2 \cdot 4^{*}$ & 0.06 & $8 \dagger$ & ND & - & ND & - \\
\hline \multicolumn{14}{|l|}{ C57BL/6JBomTac } \\
\hline Control ( $4.4 \%$ total fibre) & $19 \cdot 2$ & 0.3 & 10 & $1 \cdot 7$ & 0.3 & 10 & $2 \cdot 2$ & 0.2 & $4 \dagger$ & $0 \cdot 19$ & $1 \dagger$ & 9.6 & $1 \dagger$ \\
\hline $27 \%$ oat bran & 19.8 & 0.3 & 10 & $2 \cdot 7^{\star}$ & 0.3 & 10 & $2 \cdot 4$ & 0.1 & $4 \dagger$ & 0.21 & $1 \dagger$ & $10 \cdot 3$ & $1 \dagger$ \\
\hline Control ( $6.5 \%$ total fibre) & $19 \cdot 2$ & 0.4 & 7 & -1.0 & 0.3 & 7 & $2 \cdot 0$ & 0.1 & $4 \dagger$ & 0.29 & $1 \dagger$ & ND & - \\
\hline $40 \%$ oat bran & $18 \cdot 6$ & 0.5 & 7 & $1 \cdot 3^{*}$ & $0 \cdot 6$ & 7 & 1.9 & 0.1 & $4 \dagger$ & $0 \cdot 31$ & $1 \dagger$ & ND & - \\
\hline
\end{tabular}

$n$, numbers of observations.

Statistics were calculated with Student's unpaired $t$ test

* Significantly different between oat bran and control $(P<0.05)$

†The number refers to number of cages (in each cage, an average from seven to ten mice housed together).

bran, there was, however, no difference in body weight and feed intake between the two groups. Mean feed intake for the two B6NC experiments was $2 \cdot 1$ (SEM 0.1) g/mouse and day for control groups, and 2.3 (SEM 0.2) g/mouse and day for oat bran groups, corresponding to an energy consumption of about $40 \mathrm{~kJ}$ per mouse and day.

\section{Cholesterol excretion}

There were no marked differences in total amount of faeces collected over $24 \mathrm{~h}$ between control and oat groups (Table 3 ). Feeding mice atherogenic diet increased the cholesterol excretion approximately threefold, and, in B6NC mice, oat bran $(27 \%)$ caused an increase in cholesterol excretion compared with control diet. In contrast, there was no effect of oat bran on cholesterol excretion in B6JB mice (Table 3).

\section{Plasma lipoproteins}

The atherogenic diets induced a dramatic shift of lipoproteins towards a more human-like, atherogenic profile with elevated LDL + VLDL $v$. HDL: after treatment with the atherogenic diet, about $55 \%$ of the lipids were in the LDL + VLDL fraction, compared with $35 \%$ at baseline. Addition of oat bran resulted in a less atherogenic lipoprotein profile, with LDL + VLDL fractions of 50 and $41 \%$ in the presence of 27 and $40 \%$ oat bran, respectively, both significantly lower compared with control diets (Table 4). In B6JB mice, the effects of the atherogenic diets on lipoprotein profiles were similar to those in $\mathrm{B} 6 \mathrm{NC}$, but oat bran did not reduce the levels of LDL + VLDL in this substrain (Table 4).

\section{Plasma TAG}

The atherogenic diet induced a significant reduction in plasma TAG compared with baseline levels (Table 5). This effect has been seen earlier in C57BL/6 mice fed similar diets ${ }^{(36)}$. Oat bran in the diet did not further decrease the TAG levels, and inclusion of $27 \%$ oat bran actually increased the TAG content significantly (Table 5).

Table 4. Lipoprotein profiles in C57BL/6NCrl and JBomTac mice at baseline (normal chow) and after 4 weeks on atherogenic (Ath) diets (Mean values with their standard errors of relative amounts of lipoproteins)

\begin{tabular}{|c|c|c|c|c|c|c|c|c|c|}
\hline & \multicolumn{4}{|c|}{ HDL (\%) } & \multicolumn{4}{|c|}{ LDL and VLDL (\%) } & \multirow[b]{3}{*}{$n$} \\
\hline & \multicolumn{2}{|c|}{ Control } & \multicolumn{2}{|c|}{ Oat bran } & \multicolumn{2}{|c|}{ Control } & \multicolumn{2}{|c|}{ Oat bran } & \\
\hline & Mean & SEM & Mean & SEM & Mean & SEM & Mean & SEM & \\
\hline \multicolumn{10}{|l|}{ C57BL/6NCrl } \\
\hline Baseline & 66.4 & 1.8 & $66 \cdot 1$ & 0.9 & 33.6 & 1.8 & 33.9 & 0.9 & 10 \\
\hline Ath diet, $27 \%$ oat bran & $44 \cdot 2 \dagger \dagger$ & 0.9 & $49 \cdot 5^{\star}$ & 1.9 & $55 \cdot 8+\dagger$ & 0.9 & $50 \cdot 5^{\star}$ & 1.9 & 10 \\
\hline Ath diet, $40 \%$ oat bran & $46 \cdot 5$ & 1.9 & $58 \cdot 9^{\star \star}$ & $2 \cdot 0$ & 53.5 & 1.9 & $41 \cdot 1^{\star \star}$ & $2 \cdot 0$ & 14 \\
\hline \multicolumn{10}{|l|}{ C57BL/6JBomTac } \\
\hline Baseline & 65.9 & 1.5 & $65 \cdot 7$ & $2 \cdot 1$ & $34 \cdot 1$ & 1.5 & $34 \cdot 3$ & $2 \cdot 1$ & 10 \\
\hline Ath diet, $27 \%$ oat bran & $44.0 \dagger$ & $1 \cdot 2$ & $40 \cdot 9$ & $1 \cdot 1$ & $56 \cdot 0+\dagger$ & 1.2 & $59 \cdot 1$ & $1 \cdot 1$ & 10 \\
\hline Ath diet, $40 \%$ oat bran & 37.7 & 0.9 & $32 \cdot 1^{*}$ & $2 \cdot 2$ & $62 \cdot 3$ & 0.9 & $67.9^{\star}$ & $2 \cdot 2$ & 7 \\
\hline
\end{tabular}

Number of animals $(n)$ are shown in the right column. Statistics were calculated with Student's $t$ test.

Mean values were significantly different between oat bran and control: ${ }^{\star} P<0.05,{ }^{\star \star} P<0.001$.

Mean values were significantly different from baseline levels: $\uparrow P<0.01, \uparrow \dagger P<0.001$. (There are no baseline values available for mice fed $40 \%$ oat bran.) 
Table 5. Plasma TAG and inflammatory markers in C57BL/6NCrl and JBomTac mice after 4 weeks on atherogenic diets (Mean values with their standard errors)

\begin{tabular}{|c|c|c|c|c|c|c|c|c|c|c|c|c|}
\hline & \multicolumn{3}{|c|}{ TAG (mmol/l) } & \multicolumn{3}{|c|}{ Fibrinogen $(\mu \mathrm{g} / \mathrm{ml})$} & \multicolumn{3}{|c|}{$\mathrm{SAA}(\mu \mathrm{g} / \mathrm{ml})$} & \multicolumn{3}{|c|}{ TNF- $\alpha(p g / m l)$} \\
\hline & Mean & SEM & $n$ & Mean & SEM & $n$ & Mean & SEM & $n$ & Mean & SEM & $n$ \\
\hline \multicolumn{13}{|l|}{ C57BL/6NCrl } \\
\hline Baseline & 0.83 & 0.04 & 20 & ND & - & - & ND & - & - & ND & - & - \\
\hline Control & $0.61 \dagger$ & 0.03 & 10 & $21 \cdot 3$ & $2 \cdot 0$ & 10 & $6 \cdot 6$ & 0.5 & 10 & $30 \cdot 4$ & 1.4 & 10 \\
\hline $27 \%$ oat bran & $0.71^{*}$ & 0.03 & 10 & $20 \cdot 6$ & $2 \cdot 2$ & 10 & $6 \cdot 7$ & 0.8 & 10 & $32 \cdot 0$ & $2 \cdot 4$ & 10 \\
\hline \multicolumn{13}{|l|}{ C57BL/6JBomTac } \\
\hline Control & ND & - & - & $25 \cdot 1$ & 0.6 & 10 & $7 \cdot 3$ & 0.9 & 10 & 29.3 & 1.5 & 10 \\
\hline $27 \%$ oat bran & ND & - & - & $23 \cdot 6$ & 0.5 & 10 & $8 \cdot 0$ & 0.7 & 10 & $32 \cdot 6$ & $3 \cdot 7$ & 10 \\
\hline
\end{tabular}

$n$, numbers of observations; SAA, serum amyloid $A$.

Statistics were calculated with Student's $t$ test.

* Significantly different between oat bran and control $(P<0.05)$.

† Significantly different from baseline levels $(P<0.05)$.

\section{Plasma inflammatory markers}

Addition of $27 \%$ oat bran to the atherogenic diet did not affect the levels of fibrinogen, serum amyloid A or TNF- $\alpha$ in plasma in any of the two substrains of mice (Table 5).

\section{Discussion}

The present study shows that effects of oats on plasma cholesterol levels can be conveniently evaluated in a mouse model with observation times of weeks. Mice thus provide a useful model to evaluate how different components of oats contribute to the cholesterol-lowering effect and how processing of oats might interfere with these effects. The choice of mice as an animal model makes it possible to study not only cholesterol-lowering but also anti-atherogenic effects of oats in different GM mice available.

The mice tolerated the diet well and after an initial weight loss regained weight to exceed the initial weight at the end of the 4-week period. This is similar to earlier findings in mice fed atherogenic diets ${ }^{(37,38)}$. A slightly greater weight gain in oat-fed than in control animals has been reported in rats ${ }^{(9)}$ and, over the course of the present study, we found a slightly greater increase in mice fed $40 \%$ but not $27 \%$ oat bran. The diets were adjusted to have the same energy contents, and the food intake was similar. However, we cannot exclude that the oat bran contained minor components that affected the weight gain. We chose to use a natural oat product containing high Mp $\beta$-glucans for the present study, in order not to jeopardise the effect of the oat fibres since it has been suggested that processing can alter the structure of the fibres and hence also their bioactive effects ${ }^{(13)}$.

A possible drawback of using oat bran is that it is difficult to properly compensate for its lipid and protein contents. Although the amounts of protein and lipids were adjusted to be exactly the same in both diets, the sources of these components were different. Therefore, for example, the amounts of fatty acids in control and oat bran diets differed slightly as a result of different sources of fat (Table 2). A control experiment was performed to evaluate whether this difference had an impact on plasma cholesterol. In an alternative control diet (oil mix control), the fat in oat bran was replaced by a mixture of peanut oil (35\%), sunflower seed oil (49\%) and rapeseed oil (16\%) instead of butter to achieve an identical fatty acid composition in control and oat bran diets. Results showed that oil mix control and 'butter-only' control did not differ significantly in plasma cholesterol after 4 weeks (4.14 v. $3.98 \mathrm{mmol} / \mathrm{l}$, respectively, $n 9-10$ ), whereas oat bran diet ( $3.55 \mathrm{mmol} / \mathrm{l}, n$ 10) differed significantly from both control diets. This demonstrates that the slightly different composition of fatty acids in control and oat bran diets in the present study was not crucial for the cholesterol-lowering effect observed.

Addition of cholesterol and cholic acid to the diet is necessary to induce hypercholesterolaemia in C57BL/6 mice, since this effect is very moderate on Western diet alone ${ }^{(38)}$. This was supported in a pilot experiment where we fed C57BL/6 mice Western diet. This diet induced only a moderate increase in plasma cholesterol, which made it difficult to register significant effects of oats (data not shown). We found that the addition of $0.8 \%$ cholesterol together with $0.1 \%$ cholic acid is preferable over the commonly used concentration of $0.5 \%$. In initial experiments in the present study, we fed mice atherogenic diets with $0.5 \%$ cholic acid and found insignificant weight gain, and in some individuals even weight loss, over 4 weeks (Table 5, B6JB, $40 \%$ oat bran). High-fat diets containing added cholesterol and cholic acid are sometimes referred to as lithogenic because of their tendency to induce gallstone formation in susceptible mice strains, including C57BL/6 ${ }^{(37,39-41)}$. In the present study, gallstones were observed in some cases after feeding diets containing $0.5 \%$ cholic acid. This was, however, not seen with $0.1 \%$ cholic acid. From these observations, we conclude that the addition of cholesterol and cholic acid to the diet is a prerequisite to induce sufficient hypercholesterolaemia in C57BL/6 mice, but the concentration of cholic acid should be moderate to prevent gallstone formation.

The atherogenic diet used in the present study induced a dramatic decrease in lipids transported by HDL and increase in lipids transported by LDL and VLDL, as reported before in $\mathrm{C} 57 \mathrm{BL} / 6 \mathrm{~J}$ mice $^{(6,23,42)}$. Inclusion of 27 or $40 \%$ oat bran to the diet significantly inhibited the shift from HDL to LDL + VLDL in B6NC mice, and thus contributed to a less atherogenic lipoprotein profile. In the B6JB mice, on the other hand, oat bran in the diet did not inhibit the shift from HDL to LDL + VLDL. Oat bran did not reduce plasma TAG in the C57BL/6 mice. These findings are in line with 
the effects of oats in human subjects as reported in the metaanalysis by Kelly et al. ${ }^{(12)}$ and in rats ${ }^{(9)}$. In contrast, some later studies have reported decreased TAG in rats after consumption of oats ${ }^{(6)}$. Species or strain differences on the effects of oats on TAG levels cannot be excluded.

Studies in various infection models have shown immunomodulatory effects of $\beta$-glucans from oats both in vitro and in vivo ${ }^{(44)}$, but effects on systemic inflammation in relation to atheroclerosis are less documented. In the present study, we found no prominent effects of $27 \%$ oat bran on the systemic inflammation markers investigated (Table 5). This is in line with two human studies where consumption of oat $\beta$-glucan did not have an influence on inflammatory markers such as the acute-phase protein, C-reactive protein ${ }^{(44,45)}$. Further investigations are, however, needed to clarify whether systemic anti-inflammatory effects of oats would be observable in more advanced atherosclerosis models and if so, which component(s) in oats are effective.

Increased cholesterol excretion in subjects fed oat-based diets has earlier been found in both human ileostomy patients ${ }^{(3)}$ and hamsters ${ }^{(8)}$. Consistent with this, B6NC mice fed $27 \%$ oat bran excreted more cholesterol in faeces than control mice, whereas this was not the case with B6JB mice, which also did not respond with decreased plasma cholesterol levels. The daily intake of dietary cholesterol was on average $18 \mathrm{mg} / \mathrm{mouse}$, and although other mechanisms may contribute, the observed levels of faecal cholesterol excretion, from 7 (control) to 10 (oat bran) $\mathrm{mg} / \mathrm{d}$, are therefore likely to partly account for the reduction of plasma cholesterol in oat-fed mice.

The C57BL/6N and $\mathrm{J}$ substrains have been separated in different breeding environments for more than 50 years, and genetic differences between them have been noted in other investigations, notably in their development of alcohol dependence $^{(46)}$ and also in their cardiac responses to anaesthesia ${ }^{(47)}$. Transcriptional profiling has revealed differences in gene expression in neural tissue from the two substrains ${ }^{(46,48)}$. Recently, a mutation in a gene (Nnt) coding for a mitochondrial enzyme, nicotinamide nucleotide transhydrogenase, has been identified in C57BL/6J, but not in other B6 strains and proposed to account for their decreased glucose tolerance and insulin secretion ${ }^{(49,50)}$. The C57BL/6JBomTac substrain used in the present study was separated from the original C57BL/6J stock from Jackson laboratories three decades ago, and the Nnt mutation does not occur in C57BL/6JBom$\mathrm{Tac}^{(51)}$. To our knowledge, the substrain difference in response to oats revealed here is a novel finding and further studies are needed to explore the basis of this phenomenon. The difference in response to oats could originate from genetic variations between substrains such as single nuclotide polymorphism, but could also originate from different gene expression patterns (epigenetics) or from environmental factors, such as a divergent intestinal microflora. Composition of the microflora has recently been suggested to influence dietinduced obesity and diabetes in mice ${ }^{(52)}$. Elucidation of the mechanisms responsible for the substrain difference found here may offer new insight into mechanisms of the cholesterol-lowering effect of oats, and this could help to explain the different outcomes observed in human studies. The C57BL/6 mice have already been used for decades in studies of cholesterol-lowering drugs or dietary components ${ }^{(24-27)}$. The present finding of the substrain difference demonstrates, however, that the origin of the C57BL/6 mice used might be of importance for the outcome of the experiments.

Digestion and lipid metabolism differ in several aspects between mice and human subjects. For example, mice are coprophages and have their most fermentative activity in the caecum instead of in the colon as in human subjects, with possible impact on the intestinal microflora and the fermentation of soluble fibres. Mice also lack cholesterol ester transfer protein, which in human subjects is important for delivery of HDL cholesterol to the liver by first transferring the cholesterol from HDL to apoB-containing lipoproteins (LDL, VLDL) ${ }^{(53)}$. A large number of studies have documented effects of oats and oat fibres on cholesterol levels in human subjects $^{(12)}$. The value of the mouse model is rather that it permits studies of mechanisms, including impact on atherosclerosis development, not possible to obtain in human studies. Furthermore, the mouse model can serve as a convenient screening system for new diet ingredients before costly human trials are performed.

In conclusion, we show that C57BL/6 mice on an atherogenic diet serve a good model for systematic investigations on cholesterol-lowering effects of oat preparations, but that substrain differences occur in the responsiveness to oats. The substrain difference reported here may possibly be of use in further efforts to define the mechanistic basis for the cholesterol-lowering effect of oats.

\section{Acknowledgements}

The present work was supported by Functional Food Science Centre (FFSC) at Lund University, the Swedish Research Council (64X-28) and the Heart-Lung Foundation. All authors took part in the design of the study and evaluation of the results. K. E. A. carried out the animal experiments and associated laboratory analyses. T. I. was responsible for design, preparation and documentation of experimental diets and performed $\beta$-glucan analyses. K. E. A. and P. H. were responsible for writing the manuscript.

The authors declare no conflict of interest.

\section{References}

1. Biorklund M, van Rees A, Mensink RP, et al. (2005) Changes in serum lipids and postprandial glucose and insulin concentrations after consumption of beverages with beta-glucans from oats or barley: a randomised dose-controlled trial. Eur J Clin Nutr 59, 1272-1281.

2. Kerckhoffs DA, Brouns F, Hornstra G, et al. (2002) Effects on the human serum lipoprotein profile of beta-glucan, soy protein and isoflavones, plant sterols and stanols, garlic and tocotrienols. J Nutr 132, 2494-2505.

3. Lia A, Hallmans G, Sandberg AS, et al. (1995) Oat beta-glucan increases bile acid excretion and a fiber-rich barley fraction increases cholesterol excretion in ileostomy subjects. Am $J$ Clin Nutr 62, 1245-1251.

4. Ripsin CM, Keenan JM, Jacobs DR, et al. (1992) Oat products and lipid lowering. A meta-analysis. JAMA 267, 3317-3325.

5. Saltzman E, Das SK, Lichtenstein AH, et al. (2001) An oat-containing hypocaloric diet reduces systolic blood pressure and improves lipid profile beyond effects of weight loss in men and women. $J$ Nutr 131, 1465-1470. 
6. Czerwinski J, Bartnikowska E, Leontowicz H, et al. (2004) Oat (Avena sativa L.) and amaranth (Amaranthus hypochondriacus) meals positively affect plasma lipid profile in rats fed cholesterol-containing diets. J Nutr Biochem 15, 622-629.

7. De Schrijver R, Fremaut D \& Verheyen A (1992) Cholesterollowering effects and utilization of protein, lipid, fiber and energy in rats fed unprocessed and baked oat bran. $J$ Nutr 122, $1318-1324$

8. Delaney B, Nicolosi RJ, Wilson TA, et al. (2003) Beta-glucan fractions from barley and oats are similarly antiatherogenic in hypercholesterolemic Syrian golden hamsters. J Nutr 133, $468-475$.

9. Malkki Y, Torronen R, Pelkonen K, et al. (1993) Effects of oat-bran concentrate on rat serum lipids and liver fat infiltration. Br J Nutr 70, 767-776.

10. FDA allows whole oat foods to make health claim on reducing the risk of heart disease. In FDA Talk Paper T97-5, January 21, 1997.

11. Brown L, Rosner B, Willett WW, et al. (1999) Cholesterollowering effects of dietary fiber: a meta-analysis. Am J Clin Nutr 69, 30-42.

12. Kelly SA, Summerbell CD, Brynes A, et al. (2007) Wholegrain cereals for coronary heart disease. The Cochrane Database of Systematic Reviews CD005051.

13. Beer MU, Wood PJ, Weisz J, et al. (1997) Effect of Cooking and storage on the amount and molecular weight of $(1 \rightarrow 3)(1 \rightarrow 4) \beta$-D-glucan extracted from oat products by an in vitro digestion system. Cereal Chem 74, 705-709.

14. Andersson M, Ellegard L \& Andersson H (2002) Oat bran stimulates bile acid synthesis within $8 \mathrm{~h}$ as measured by 7alpha-hydroxy-4-cholesten-3-one. Am J Clin Nutr 76, $1111-1116$.

15. Blackburn NA, Redfern JS, Jarjis H, et al. (1984) The mechanism of action of guar gum in improving glucose tolerance in man. Clin Sci (Lond) 66, 329-336.

16. Drzikova B, Dongowski G \& Gebhardt E (2005) Dietary fibrerich oat-based products affect serum lipids, microbiota, formation of short-chain fatty acids and steroids in rats. $\mathrm{Br} J$ Nutr 94, 1012-1025.

17. Lund EK, Gee JM, Brown JC, et al. (1989) Effect of oat gum on the physical properties of the gastrointestinal contents and on the uptake of D-galactose and cholesterol by rat small intestine in vitro. Br J Nutr 62, 91-101.

18. Theuwissen E \& Mensink RP (2008) Water-soluble dietary fibers and cardiovascular disease. Physiol Behav 94, 285-292.

19. Wood PJ, Braaten JT, Scott FW, et al. (1994) Effect of dose and modification of viscous properties of oat gum on plasma glucose and insulin following an oral glucose load. Br J Nutr 72, 731-743.

20. Yang JL, Kim YH, Lee HS, et al. (2003) Barley beta-glucan lowers serum cholesterol based on the up-regulation of cholesterol 7alpha-hydroxylase activity and mRNA abundance in cholesterol-fed rats. J Nutr Sci Vitaminol (Tokyo) 49 381-387.

21. Peterson D (2001) Oat antioxidants. J Cereal Sci 33, 115-129.

22. Pettersson D \& Åman P (1992) Production responses and serum lipid concentration of broiler chickens fed diets based on oat bran and extracted oat bran with and without enzyme supplementation. J Sci Food Agric 58, 569-576.

23. Paigen B, Mitchell D, Reue K, et al. (1987) Ath-1, a gene determining atherosclerosis susceptibility and high density lipoprotein levels in mice. Proc Natl Acad Sci U S A 84, 3763-3767.

24. Kirk EA, Sutherland P \& Wang SA (1998) Dietary isoflavones reduce plasma cholesterol and atherosclerosis in C57BL/6 mice but not LDL receptor-deficient mice. $J$ Nutr 128, 954-959.
25. Chan MY \& Heng CK (2008) Sequential effects of a high-fiber diet with psyllium husks on the expression levels of hepatic genes and plasma lipids. Nutrition 24, 57-66.

26. Matsumoto K, Watanabe Y, Ohya MA, et al. (2006) Young persimmon fruits prevent the rise in plasma lipids in a diet-induced murine obesity model. Biol Pharm Bull 29, 2532-2535.

27. Murakami S, Kondo-Ohta Y \& Tomisawa K (1999) Improvement in cholesterol metabolism in mice given chronic treatment of taurine and fed a high-fat diet. Life Sci 64, $83-91$.

28. Hundemer JK, Nabar SP, Shriver BJ, et al. (1991) Dietary fiber sources lower blood cholesterol in C57BL/6 mice. J Nutr 121, $1360-1365$.

29. J Overton (editor) (1995) Nutrient requirement of the mouse. In Nutrient Requirements of Laboratory Animals, 4th ed., pp. 80-102. National Research Council. Washington: National Academy Press.

30. Fulcher R (1986) Morphological and chemical characterization of the oat kernel. In Oats: Chemistry and Technology, pp. 47-73 [F Webster, editor]. St Paul, MN: American Association of Cereal Chemists.

31. McCleary BV \& Codd R (1991) Measurement of $(1 \rightarrow 3)$, $(1 \rightarrow 4)$-beta-glucan in barley and oats: a streamlined enzymic procedure. J Sci Food Agric 55, 303-312.

32. Tosh SM, Brummer Y, Wolever TMS, et al. (2008) Glycemic response to oat bran muffins treated to vary molecular weight of $\beta$-glucan. Cereal Chem 85, 211-217.

33. Noble RP (1968) Electrophoretic separation of plasma lipoproteins in agarose gel. J Lipid Res 9, 693-700.

34. Hara A \& Radin NS (1978) Lipid extraction of tissues with a low-toxicity solvent. Anal Biochem 90, 420-426.

35. Lindegaard ML, Damm P, Mathiesen ER, et al. (2006) Placental triglyceride accumulation in maternal type 1 diabetes is associated with increased lipase gene expression. $J$ Lipid Res 47, 2581-2588.

36. Schreyer SA, Wilson DL \& LeBoeuf RC (1998) C57BL/6 mice fed high fat diets as models for diabetes-accelerated atherosclerosis. Atherosclerosis 136, 17-24.

37. Kasbo J, Tuchweber B, Perwaiz S, et al. (2003) Phosphatidylcholine-enriched diet prevents gallstone formation in mice susceptible to cholelithiasis. J Lipid Res 44, 2297-2303.

38. Nishina PM, Verstuyft J \& Paigen B (1990) Synthetic low and high fat diets for the study of atherosclerosis in the mouse. J Lipid Res 31, 859-869.

39. Tepperman J, Caldwell FT \& Tepperman HM (1964) Induction of gallstones in mice by feeding a cholesterol-cholic acid containing diet. Am J Physiol 206, 628-634.

40. Khanuja B, Cheah YC, Hunt M, et al. (1995) Lith1, a major gene affecting cholesterol gallstone formation among inbred strains of mice. Proc Natl Acad Sci U S A 92, 7729-7733.

41. Maurer KJ, Rogers AB, Ge Z, et al. (2006) Helicobacter pylori and cholesterol gallstone formation in $\mathrm{C} 57 \mathrm{~L} / \mathrm{J}$ mice: a prospective study. Am J Physiol Gastrointest Liver Physiol 290, G175-G182.

42. Ishida BY, Blanche PJ, Nichols AV, et al. (1991) Effects of atherogenic diet consumption on lipoproteins in mouse strains C57BL/6 and C3H. J Lipid Res 32, 559-568.

43. Volman JJ, Ramakers JD \& Plat J (2008) Dietary modulation of immune function by beta-glucans. Physiol Behav 94, 276-284.

44. Queenan KM, Stewart ML, Smith KN, et al. (2007) Concentrated oat beta-glucan, a fermentable fiber, lowers serum cholesterol in hypercholesterolemic adults in a randomized controlled trial. Nutr $J \mathbf{6}, 6$.

45. Theuwissen E, Plat J \& Mensink RP (2009) Consumption of oat beta-glucan with or without plant stanols did not influence inflammatory markers in hypercholesterolemic subjects. Mol Nutr Food Res 53, 370-376. 
46. Mulligan MK, Ponomarev I, Boehm SL, et al. (2008) Alcohol trait and transcriptional genomic analysis of $\mathrm{C} 57 \mathrm{BL} / 6$ substrains. Genes Brain Behav 7, 677-689.

47. Roth DM, Swaney JS, Dalton ND, et al. (2002) Impact of anesthesia on cardiac function during echocardiography in mice. Am J Physiol Heart Circ Physiol 282, H2134-H2140.

48. Green ML, Singh AV, Zhang Y, et al. (2007) Reprogramming of genetic networks during initiation of the fetal alcohol syndrome. Dev Dyn 236, 613-631.

49. Toye AA, Lippiat JD, Proks P, et al. (2005) A genetic and physiological study of impaired glucose homeostasis control in C57BL/6J mice. Diabetologia 48, 675-686.

50. Freeman HC, Hugill A, Dear NT, et al. (2006) Deletion of nicotinamide nucleotide transhydrogenase: a new quantitive trait locus accounting for glucose intolerance in C57BL/6J mice. Diabetes 55, 2153-2156.

51. Taconic (2008) C57BL/6JBomTac, C57BL/6NTac and C57BL/ 10SgSnAiTac mice do not carry the Nnt mutation. http://www. taconic.com/user-assets/Documents/Nnt_Mutation.pdf (accessed January 2009).

52. Cani PD, Bibiloni R, Knauf C, et al. (2008) Changes in gut microbiota control metabolic endotoxemia-induced inflammation in high-fat diet-induced obesity and diabetes in mice. Diabetes 57, 1470-1481.

53. Rader DJ, Alexander ET, Weibel GL, et al. (2008) Role of reverse cholesterol transport in animals and humans and relationship to atherosclerosis. J Lipid Res $\mathbf{5 0 ,}$ S189-S194. 